\title{
In Memoriam of Prof. Henri M. Duvernoy (1931-2021)
}

\author{
Laurent Tatu $^{\mathrm{a}, \mathrm{b}}$ Thierry Moulin ${ }^{\mathrm{a}} \quad$ Julien Bogousslavsky ${ }^{\mathrm{c}}$ \\ ${ }^{a}$ Department of Neurology, CHRU, Besançon, France; b Department of Anatomy, University of Franche-Comté, Besançon, \\ France; ${ }^{C}$ Center for Brain and Nervous System Disorders, Swiss Medical Network, Clinique Valmont, Glion, Switzerland
}

Henri Duvernoy, one of the key figures of neuroanatomy in the 20th century, passed away on May 11, 2021, at the age of 90 years. For almost 40 years, he was based at the faculty of medicine of the University of FrancheComté in Besançon in Eastern France (Fig. 1). He lectured in anatomy and conducted internationally renowned research with a particular focus on brain microvascularization and the anatomy of the hippocampus.

Duvernoy grew up in a medical family: his father Maurice (1885-1985) was professor of anatomy at the Besançon Medical School and took on the role of dean shortly after the Second World War. Henri Duvernoy completed the first part of his medical studies in Besançon before qualifying as a medical doctor at the Faculté de médecine of Paris in 1958. Returning to Besançon, he was appointed professor in 1962 and later became head of the anatomy department, bringing an international recognition to the laboratory his father had founded.

He was encouraged to study the micro-architecture of cerebral vessels by his mentor Roger Guillemin, whose work in neuroendocrinology gained him the Nobel Prize in Medicine or Physiology in 1977. Meticulous to the point of obsession, Duvernoy produced some of the most realistic and informative neuroanatomic works available

karger@karger.com

(c) 2021 S. Karger AG, Basel

www.karger.com/ene to anatomists, illustrated by Jean-Louis Vannson. These works, which he began before the advent of neuroimaging, have now become essential tools in the fields of epilepsy, stroke, and neurosurgery and have had a major impact on patient care.

He leaves the rich legacy of these decades of neuroanatomy research, having published many reference

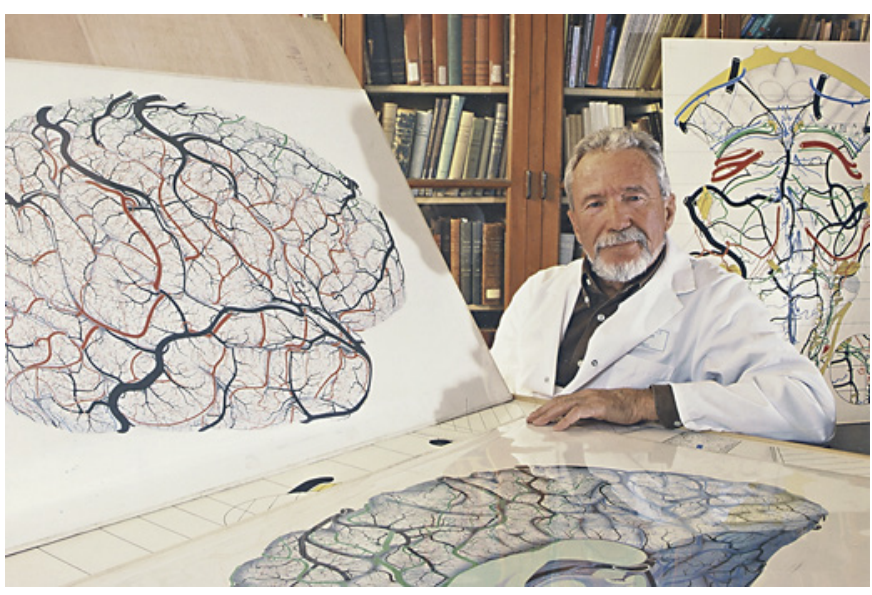

Fig. 1. Henri M. Duvernoy (1931-2021). 
works, from his first book in 1975 (The superficial veins of the human brain) to his last opus in 2007 (Duvernoy's atlas of the human brain, brainstem and cerebellum). Well into his retirement, and for as long as his health allowed, Prof. Duvernoy continued to collaborate on neuroanatomical projects and studies. His retirement also gave him more time to enjoy his other passions - being in the mountains and cross-country skiing with his wife Odile and 2 sons - Charles and David.

His pioneering work in the study of cerebral microvascularization led to key practical developments in the field of cerebrovascular diseases. For the 3 authors of this obituary, it is an honor to have worked with him on one of the most important applications, which is now integrated into the daily practices of stroke specialists (Arterial territories of human brain, brainstem and cerebellum 1996-1998).

His students and successors in the approach to anatomy he created are infinitely indebted to him for his guidance and teaching. His scientific rigor and unique perspective on neuroanatomy will live on through those who follow in his footsteps.

\section{Conflict of Interest Statement}

The authors have no conflicts of interest to declare. 